\title{
Protonating Polymer Oligomers in the Gas Phase to Change Fragmentation Pathways
}

\author{
Abdulrahman M. Alhazmi and Paul M. Mayer \\ Department of Chemistry, University of Ottawa, Ottawa, Ontario, Canada
}

Ionization of polymers in mass spectrometry is usually achieved by forming metal ion adducts. The metal ion has been shown by Wesdemiotis to often play a spectator role in the collision-induced dissociation (CID) chemistry of these species, wherein they fragment according to a free-radical mechanism similar to that found in their pyrolysis. The result is a predominance of low-mass ions in the CID mass spectrum. We have changed this behavior by generating protonated oligomers in the gas phase by first forming proton-bound complexes of the oligomers with amino acids or peptides by electrospray ionization. These complexes dissociate first by loss of the amino acid/peptide to form protonated oligomers, which then undergo a unique fragmentation chemistry. In this article we discuss the results for poly(methyl methacrylate) (PMMA) and poly(butyl acrylate) (PBA). Initially, protonated PMMA and PBA lose methanol and butanol, respectively, from the side chains of the respective monomers. The resulting PMMA-derived ion then undergoes a series of neutral losses corresponding to 32 and $28 \mathrm{Da}$, methanol and carbon monoxide. This continues as collision energy increases until a final, carbon-rich backbone ion is formed, which then undergoes a classic hydrocarbon fragmentation pattern. The PBA-derived ions are proposed to fragment by the loss of butylether molecules to form anhydride rings along the oligomer chain. The number of ether molecules lost corresponded to half the number of available side chains in the oligomer. The resulting poly-anhydride ion dissociates by small molecule loss. Mechanisms have been suggested for the fragmentation chemistry of these two classes of oligomers. (J Am Soc Mass Spectrom 2009, 20, 60-66) (c) 2009 Published by Elsevier Inc. on behalf of American Society for Mass Spectrometry

A though the predominant mode of ionization for peptides and proteins in mass spectrometry is protonation in solution, the same cannot be said for synthetic polymers. Typically, synthetic polymers such as poly(methyl methacrylate) (PMMA) are not basic enough in solution to acquire a proton from an added acid. To overcome this limitation, salts incorporating metal ions are usually added to the polymer/ solvent solution before electrospray ionization (ESI) (or to the polymer/matrix solution before ionization by matrix-assisted laser desorption/ionization). This generates gas-phase polymer oligomers ionized by the metal ion. This has consequences for the analysis of these oligomers by collision-induced dissociation (CID) mass spectrometry. For example, Jackson and Scrivens studied poly(alkyl methacrylates) (PAMAs), i.e., PMMA and poly(n-butyl methacrylate) (PBMA) by different mass spectrometry techniques [1-7]. In each case the CID mass spectrum was dominated by low mass-to-charge ratio $(\mathrm{m} / \mathrm{z})$ fragment ions. In the case of PMMA the fragments were proposed to be generated mainly by homolytic cleavage and 1,5 hydrogen rearrangement reactions along the polymer backbone $[2,7]$.

Address reprint requests to Prof. Paul Michael Mayer, University of Ottawa, Department of Chemistry, 10 Marie-Curie, Ottawa, Ontario, Canada K1N 6N5. E-mail: pmmayer@uottawa.ca
Low-intensity peaks at high $\mathrm{m} / \mathrm{z}$ were assumed to be formed by neutral losses and fragmentation along the polymer backbone [5]. The end result was a variety of fragment ion progressions each differing by one monomer unit. Bowers et al. proposed a mechanism that rationalized the predominance of the low $\mathrm{m} / \mathrm{z}$ fragments. MM/MD simulations demonstrated that the oligomer/metal ion adduct takes on a quasi-cyclic structure. Upon collisional activation this ring opens, leaving the metal ion attached to either end of the oligomer. The metal ion drives the fragmentation near the end of the oligomer, producing low $\mathrm{m} / \mathrm{z}$ fragments ions [4]. An alternative mechanism has been proposed by Wesdemiotis et al. in which the metal ion acts as a spectator as the oligomer undergoes what is essentially a free-radical decomposition pathway similar to that which occurs during pyrolysis [8,9]. Also Hercules et al. studied PAMAs by time-of-flight secondary ion mass spectrometry (SIMS) [10]. The dominant dissociation channel was found to be ester group (COOR) loss from the side chain, similar to that found in Scrivens' homolytic cleavage scheme [3]. Two other pathways were found: methyl group loss followed by backbone cleavage and just simple backbone cleavage.

We sought to explore the difference protonation would make on the oligomer ion decomposition pathways. Since it is very difficult to form such species in
(C) 2009 Published by Elsevier Inc. on behalf of American Society for Mass Spectrometry. 1044-0305/09/\$32.00

doi:10.1016/j.jasms.2008.09.014
Published online September 23, 2008 Received June 10, 2008 Revised September 11, 2008 Accepted September 11, 2008 


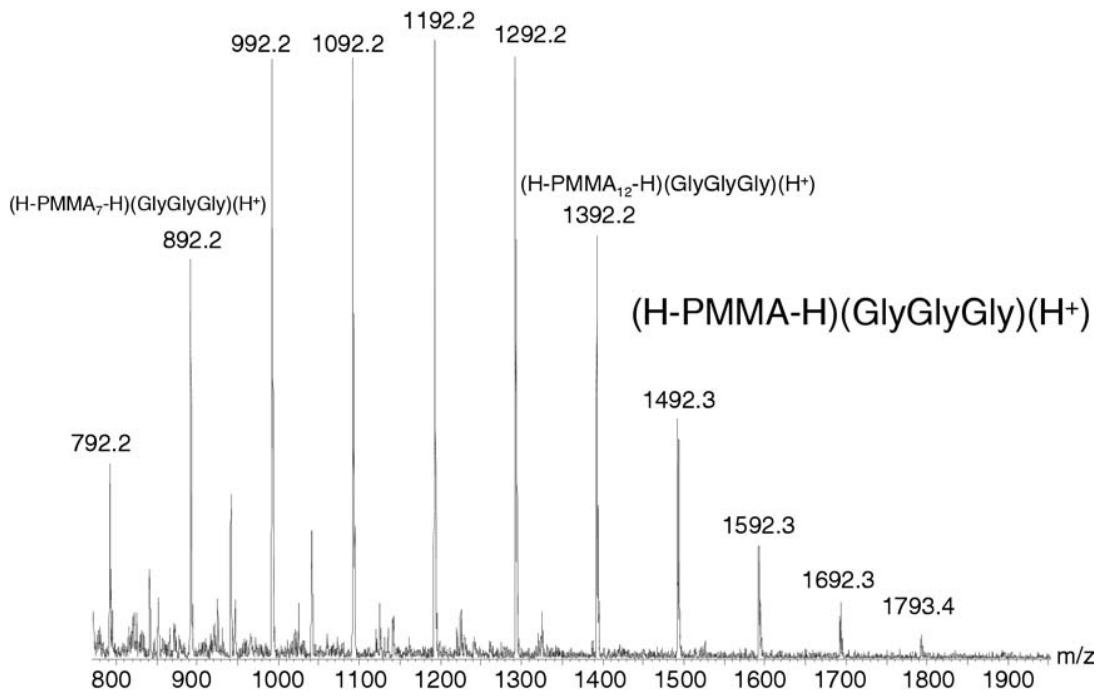

Figure 1. ESI-MS mass spectrum of PMMA ionized by protonated triglycine (H-PMMA $\mathrm{H})\left(\right.$ GlyGlyGly) $\mathrm{H}^{+}$. The minor distribution is mainly PMMA ionized by $\mathrm{Na}^{+}$coming from the glassware.

solution, they were generated in the gas phase by using ESI to first form proton-bound complexes between the oligomers and small peptides or amino acids. As will be seen, these protonated oligomer ions undergo a unique fragmentation chemistry upon collisional activation.

\section{Experimental}

\section{Materials}

Acetonitrile was purchased from Fisher Scientific (Pittsburgh, PA, USA) and amino acids, peptides, and formic acid were purchased from Sigma-Aldrich (Milwaukee, WI, USA). PMMA (Mw: 1460, Mw/Mn : 1.07) and PBA (Mw: 1630, Mw/Mn : 1.13) were purchased from Polymer Laboratories (Amherst, MA, USA) and Polymer Source Inc. (Montreal, QC, Canada), respectively.

\section{Electrospray Ionization Mass Spectrometry (ESI-MS)}

ESI-MS experiments were performed using a Micromass Quattro LC triple quadrupole mass spectrometer (Waters Micromass, Manchester, UK) equipped with a Z-spray ion source. Polymer and amino acid or peptide were each dissolved in acetonitrile and water (8:2; $\mathrm{vol} / \mathrm{vol}$ ) then mixed to make a solution $1: 1$ or $1: 280$ (c/c) polymer:amino acid/peptide. Several drops of 5\% formic acid were added. The ESI capillary was operated at $4 \mathrm{kV}$ and sample cone voltage was set to $40 \mathrm{~V}$. The solutions were introduced into the system by syringe pump at a rate of $40 \mu \mathrm{L} \mathrm{min}{ }^{-1}$. Argon was used as collision gas with pressures from $2.0 \times 10^{-4}$ to $2.0 \times$ $10^{-3}$ mbar, depending on the experiment (specific conditions will be given in each figure capture).

\section{Results and Discussion}

Poly(methyl methacrylate)

The mass spectrum of PMMA ionized by protonated triglycine (GlyGlyGly) (Figure 1) shows a distribution of ions with $\mathrm{m} / \mathrm{z}$ values of $792,892,992,1092$, and so forth, representing $\left(\mathrm{H}-\mathrm{PMMA}_{n}-\mathrm{H}\right)(\mathrm{GlyGlyGly}) \mathrm{H}^{+}$, where $n$ is the number of MMA units and $H$ represents the two oligomer end groups. One monomer unit of MMA is $100 \mathrm{Da}$ and neutral GlyGlyGly is $189 \mathrm{Da}$. When diglycine (GlyGly) was used, the peak $\mathrm{m} / \mathrm{z}$ values were reduced by 57 Da to give a progression with $\mathrm{m} / \mathrm{z}$ values of 735, 835, 935, 1035, and so forth (Supplementary Figure S1a, which can be found in the electronic version of this article). Ionized PMMA oligomer ions were also generated separately with several amino acids (Gly, Ala, Leu, Phe, Trp, Asp, Lys, and Arg), each giving the corresponding distribution, which can generically be written as $\left(\mathrm{H}-\mathrm{PMMA}_{n}-\mathrm{H}\right)(\mathrm{AA}) \mathrm{H}^{+}$, where $\mathrm{AA}$ is the amino acid.

Figure 2 shows the $\mathrm{CID}$ mass spectrum of $(\mathrm{H}-$ $\left.\mathrm{PMMA}_{10}-\mathrm{H}\right)($ GlyGlyGly$) \mathrm{H}^{+}$. The dominant fragment ions are at high $m / z$ and only GlyGlyGly $\mathrm{H}^{+}$is seen in the low $m / z$ region of the mass spectrum. Fragmentation is completely different from that observed when alkali metal ions are used for ionization [2-5, 7]. In Figure 2, an initial loss of $221 \mathrm{Da}$ is observed corresponding to neutral GlyGlyGly (189 Da) plus a molecule of methanol (32 Da) from one of the monomer side chains. When GlyGlyGly is replaced by GlyGly (Supplementary Figure S1b), the initial neutral loss was $164 \mathrm{Da}$, a decrease attributed to the 57-Da mass difference between the two peptides. The loss of methanol occurs from a protonated oligomer after the initial loss of the peptide (Scheme 1), a sequence supported by the observation of the protonated oligomer 


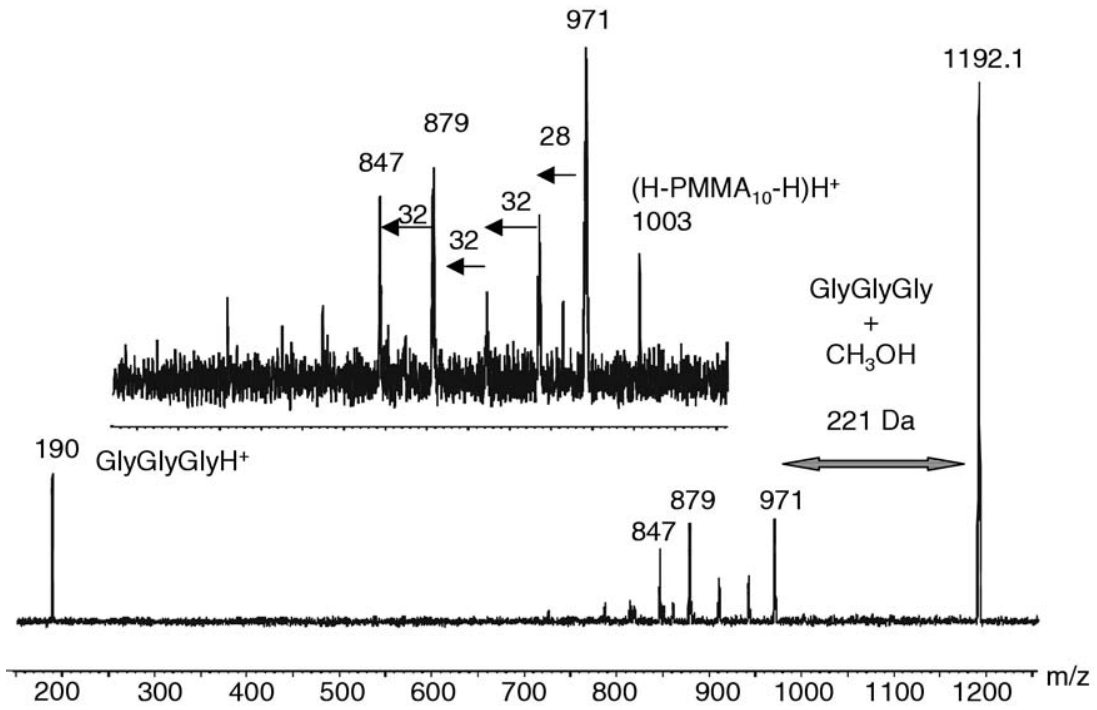

Figure 2. CID mass spectrum of $\left(\mathrm{H}-\mathrm{PMMA}_{10}-\mathrm{H}\right)($ GlyGlyGly $) \mathrm{H}^{+}, \mathrm{m} / z 1192\left(\mathrm{E}_{\text {coll }}=30 \mathrm{eV}\right.$, pressure $=2.0 \times 10^{-3}$ mbar). Inset shows the protonated ion $\left(\mathrm{H}-\mathrm{PMMA}_{10}-\mathrm{H}\right) \mathrm{H}^{+}, \mathrm{m} / z$ 1003, after the loss of the neutral GlyGlyGly at $\mathrm{E}_{\text {coll }}=27 \mathrm{eV}$.

$\left(\mathrm{H}-\mathrm{PMMA}_{10}-\mathrm{H}\right) \mathrm{H}^{+}$in the CID mass spectrum at low collision energy (CE) (Figure 2, inset).

After the initial loss of methanol the resulting oligomer cation produces a mass spectrum dominated by peaks separated by 28 and $32 \mathrm{Da}$. At least the first loss of $28 \mathrm{Da}$ is consistent with CO loss from an acylium ion structure. Secondary and tertiary acylium ions such as those produced from methanol loss from a methyl methacrylate monomer have a low-energy threshold to CO loss [11], which is why the peak with $\mathrm{m} / \mathrm{z} 971$ in Figure 2 is dominant only at very low collision energy. No loss corresponding to the mass of one momoner unit (100 Da) is observed at any collision energy. Therefore, these fragmentation reactions do not happen along the backbone of the oligomer cation, but rather involve the side chains, leaving the backbone at least partially intact. Figure 3 demonstrates how the fragmentation pattern changes as a function of collision energy for $\left(\mathrm{H}-\mathrm{PMMA}_{9}-\mathrm{H}\right) \mathrm{H}^{+}$, highlighting the peak separations of 28 and $32 \mathrm{Da}$. The dominant fragment ion peaks change from high $\mathrm{m} / \mathrm{z}$ at low $\mathrm{CE}$ to low $\mathrm{m} / \mathrm{z}$ at high CE, indicating substantial consecutive fragmentation with increasing CE. An enlargement of each mass spectrum in Figure 3 can be found in Supplementary Figure S2. At the beginning of oligomer cation fragmentation there are relatively more "losses" of 32 than $28 \mathrm{Da}$, but as the $\mathrm{CE}$ increases the two peak separations become more sequential (see $65 \mathrm{eV}$ ). Counting the initial loss of methanol, the mass spectra at 35 and $65 \mathrm{eV}$ show the loss of methanol from all nine side chains of this 9-mer. Only six losses of $28 \mathrm{Da}$ are observed as CE increases. There is also a lower intensity progression of fragment ions 18 Da lower in $\mathrm{m} / \mathrm{z}$ because of the loss of $\mathrm{H}_{2} \mathrm{O}$ (annotated by the asterisk in Figure 3) from $\mathrm{m} / \mathrm{z} 779$. Once the oligomer cation has lost the equivalence of all nine methoxy groups and six $\mathrm{CO}$ units it lands up with $\mathrm{m} / \mathrm{z} 447\left(\mathrm{~m} / \mathrm{z} 429\right.$ has the additional loss of $\left.\mathrm{H}_{2} \mathrm{O}\right)$. Both progressions of fragment ions undergo further loss of three units of $28 \mathrm{Da}$ (and $\mathrm{H}_{2} \mathrm{O}$ for the case of the major progression) to finally produce $\mathrm{m} / \mathrm{z} 345$, which reflects the backbone of the oligomer. This is supported by the high intensity of $\mathrm{m} / \mathrm{z} 345$ and the fact that sequential losses of 32 and $28 \mathrm{Da}$ are no longer observed from this ion. Rather, peaks separated by 14 and $12 \mathrm{Da}$ are

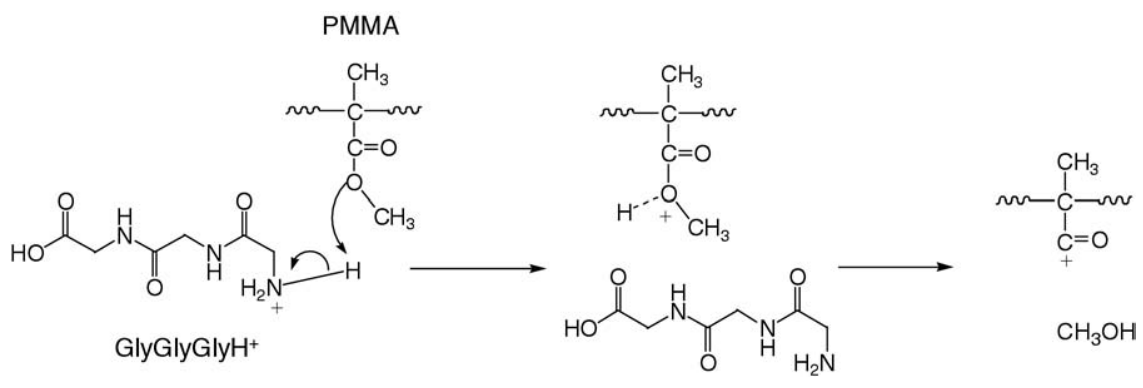




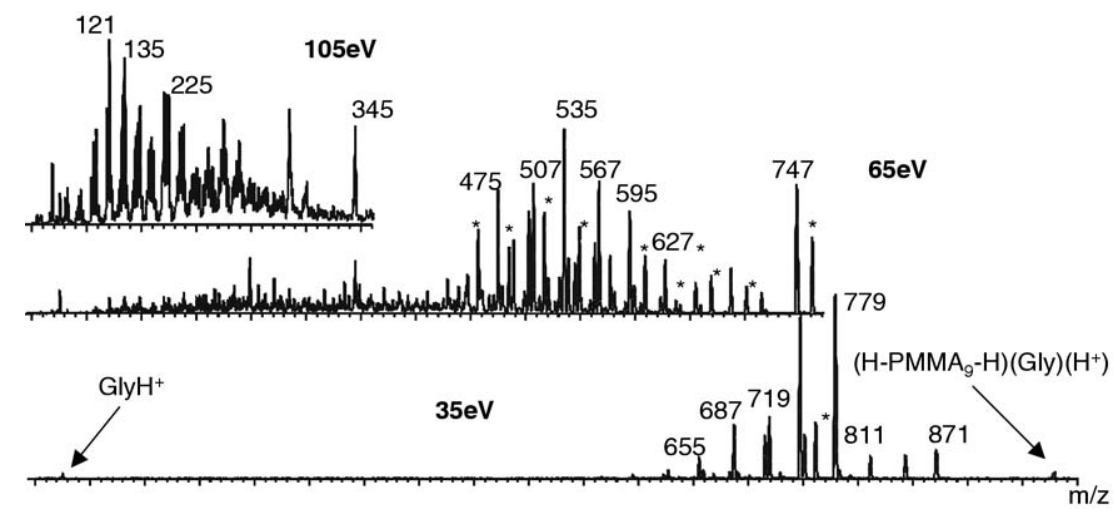

Figure 3. CID mass spectrum of $\left(\mathrm{H}-\mathrm{PMMA}_{9}-\mathrm{H}\right)(\mathrm{Gly}) \mathrm{H}^{+}, m / z$ 978, at three different collision energies: 35,65 , and $105 \mathrm{eV}$ (pressure $=2.0 \times 10^{-3}$ mbar). The asterisk $\left(^{*}\right)$ denotes the minor fragmentation progression in which $\mathrm{H}_{2} \mathrm{O}$ is lost early in the sequence (see text).

observed, consistent with the fragmentation of a hydrocarbon chain (Figure 3, $105 \mathrm{eV}$ ). The fragmentation pathways are illustrated in Scheme 2. Of course, what

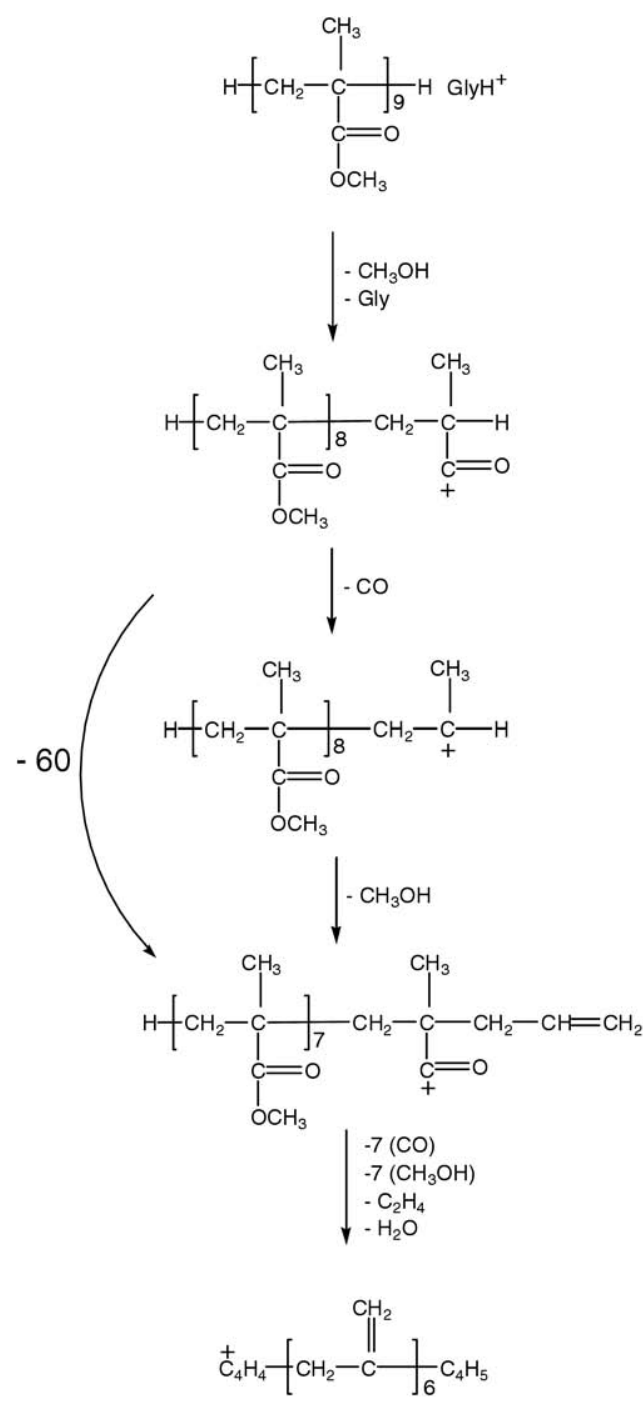

$\mathrm{m} / \mathrm{z} 978$

$\mathrm{m} / \mathrm{z} 871$

$\mathrm{m} / \mathrm{z} 843$

$\mathrm{m} / \mathrm{z} 811$

$\mathrm{m} / \mathrm{z} 345$

Scheme 2 is presented above is only a suggested sequence of events; without the ability to independently generate each intermediate in isolation it is impossible to prove the sequence. Attempts are complicated by the fact that the initial loss of methanol can occur from any of the monomer side chains and each of these resulting ions can fragment to its own degree. What is clear is that a simplistic arrow-pushing exercise starting with the protonated oligomer cannot account for the sequence of fragment ions. Likely, intramolecular reactions may be involved, perhaps similar to that generating the oxazolone-based structure of the b-ion in peptide ion fragmentation.

\section{Poly(butyl acrylate)}

Poly(butyl acrylate) oligomers also generate complexes with protonated GlyGlyGly (Supplementary Figure S3a). The mass spectrum exhibited four distinct ion distributions: one major one, $\left(\mathrm{Bu}-\mathrm{PBA}_{n}-\right.$ $\mathrm{H})\left(\right.$ GlyGlyGly) $\left.\mathrm{H}^{+}\right)$; and three with lower abundance, $\left(\mathrm{Bu}-\mathrm{PBA}_{n}-\mathrm{H}\right) \mathrm{Na}^{+}$(from residual sodium), $\left(\mathrm{CH}_{3} \mathrm{O}-\right.$ $\left.\mathrm{PBA}_{n}-126-\mathrm{OCH}_{3}\right)\left(\right.$ GlyGlyGly) ${ }_{2}\left(\mathrm{H}^{+}\right)_{2}$ (where 126 is an unsaturated BA unit $\left(\mathrm{C}_{7} \mathrm{H}_{10} \mathrm{O}_{2}\right)$, and the methoxy groups come from the terminator $\left(\mathrm{CH}_{3} \mathrm{OH}\right)$ used in the synthesis [12] and PBA ionized with GlyGlyGlyH ${ }^{+}$and terminated with an unidentified 80-Da end group (this end group likely originates from the alkyl lithium initiator system used to make PBA [12,13]. As for PMMA, we were able to generate proton-bound complexes of PBA oligomers with different peptides and amino acids, represented by the generic formula $\left(\mathrm{PBA}_{n}\right)(\mathrm{AA}) \mathrm{H}^{+}$.

The CID mass spectrum of $\left(\mathrm{Bu}-\mathrm{PBA}_{8}-\mathrm{H}\right)$ (GlyGlyGly) $\mathrm{H}^{+}$(Figure 4) shows a loss of $263 \mathrm{Da}$, which corresponds to butanol (74 Da) and neutral GlyGlyGly. This was confirmed by observing the 57-Da decrease in this loss when GlyGlyGly was replaced with GlyGly (Supplementary Figure S3b). After the initial loss of butanol and the peptide, the protonated PBA undergoes sequential losses of $130 \mathrm{Da}$. This $130 \mathrm{Da}$ is butyl ether lost from the PBA side chains and not a rearranged BA 


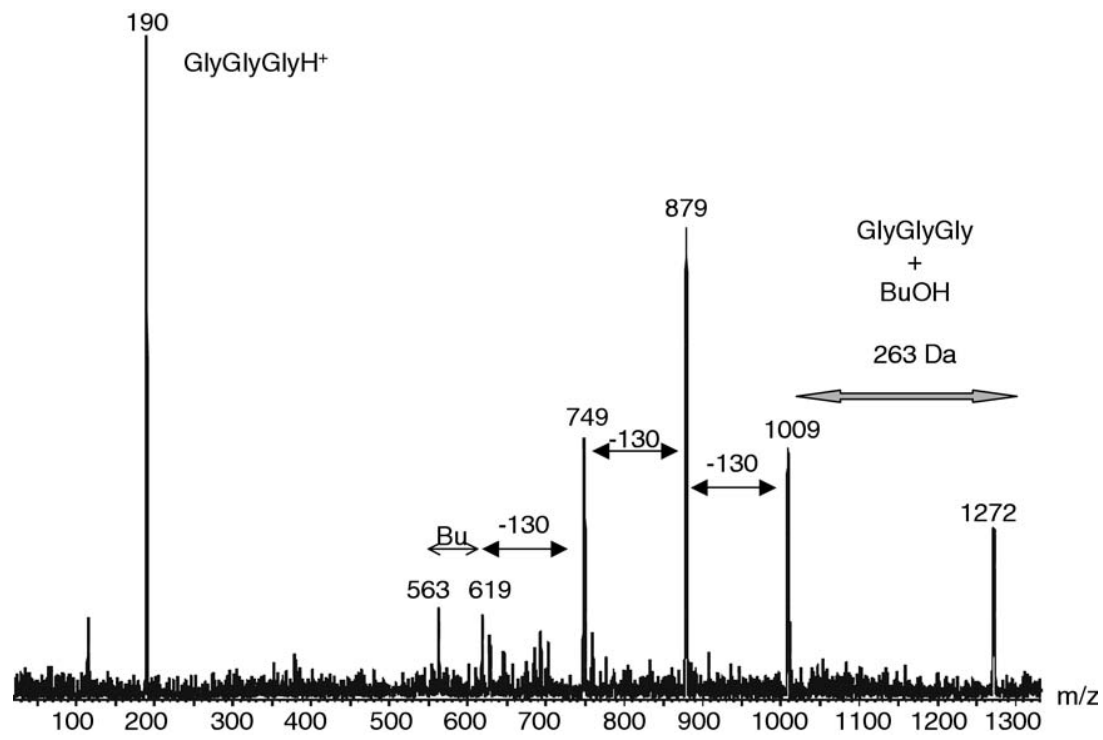

Figure 4. $\mathrm{CID}$ mass spectrum of $\left(\mathrm{Bu}-\mathrm{PBA}_{8}-\mathrm{H}\right)(\mathrm{GlyGlyGly}) \mathrm{H}^{+}, m / z 1272\left(\mathrm{E}_{\text {coll }}=40 \mathrm{eV}\right.$, pressure $=$ $\left.2.0 \times 10^{-3} \mathrm{mbar}\right)$.

unit cleaved from the backbone. The number of butyl ether losses agrees with the number of PBA side chains in the oligomer. For example, a 7-mer has seven-OBu units and since one is lost in the initial step of the fragmentation, it can only lose three butyl ether molecules (Supplementary Figure S4). This is also true for the 8-mer (Figure 4). If the loss of $130 \mathrm{Da}$ was attributed to BA units along the backbone by double H-transfer, one would expect the CID mass spectrum of the 8-mer to exhibit one more of these losses than that of 7-mer. The number of butyl ether losses will increase as the number of BA units increases and is the same for oligomers with sequential odd and even number of BA units (see Supplementary Figure S4 for the CID mass spectra of the 7-mer, 9-mer, 11-mer, and 13-mer for comparison). For comparison, the CID mass spectrum of $\left(\mathrm{Bu}-\mathrm{PBA}_{9}-\mathrm{H}\right) \mathrm{Na}^{+}$shows this loss of $130 \mathrm{Da}$, but is dominated by butene and butanol losses (Figure 5 (also see Chaicharoen et al. [9]). Ionizing PBA with $\mathrm{Na}^{+}$does not allow the loss of all the monomer side chains as in protonated PBA. This may be explained by the competition from the other fragmentation pathways occurring along the backbone to form $\left(\mathrm{BA}_{n}\right) \mathrm{Na}^{+}$(Figure 5). Losses of butene and/or butanol are also observed from protonated PBA, but only after the oligomer loses the maximum number of butyl ether molecules (Figure 4, Supplementary Figure S4), and only as minor processes at high CE. The losses of butene and butanol likely occur by side-chain reactions similar to their formation in the thermal degradation of PBA $[9,14,15]$. First, the ester butyl group will form a six-membered ring transition state, which then eliminates butene, leaving an acrylic acid unit in the PBA side chain (Scheme 3). Second, butene could form in the same manner from another side chain, or the acrylic acid unit reacts with a neighboring butyl ester to form butanol and a cyclic

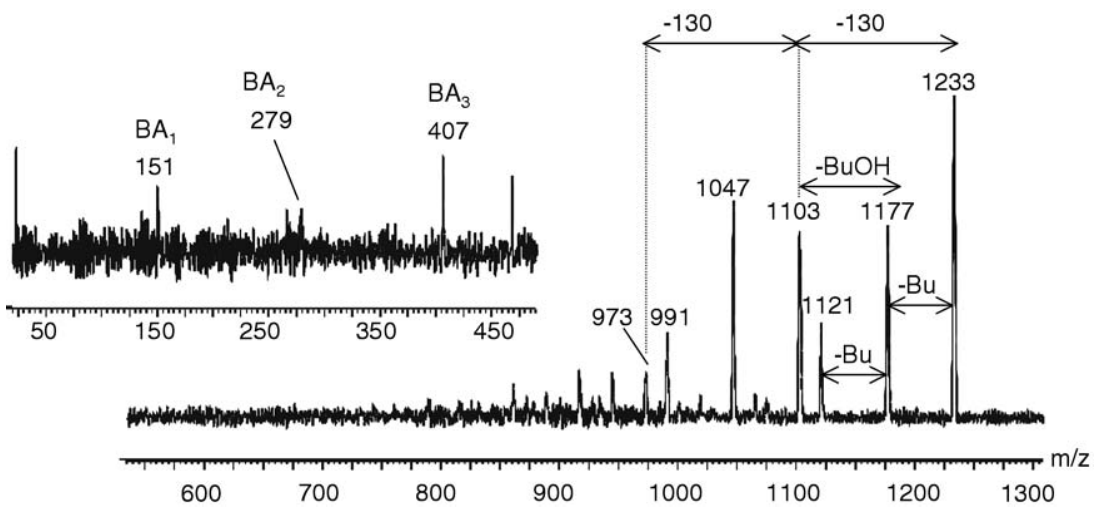

Figure 5. CID mass spectrum of $\left(\mathrm{Bu}-\mathrm{PBA}_{9}-\mathrm{H}\right) \mathrm{Na}^{+}, m / z 1233\left(\mathrm{E}_{\mathrm{coll}}=80 \mathrm{eV}\right.$, pressure $=2.0 \times 10^{-4}$ mbar), $-\mathrm{Bu}$ in the figure is the loss of butene (56 Da). The inset shows the low $\mathrm{m} / \mathrm{z}$ region of the mass spectrum. 


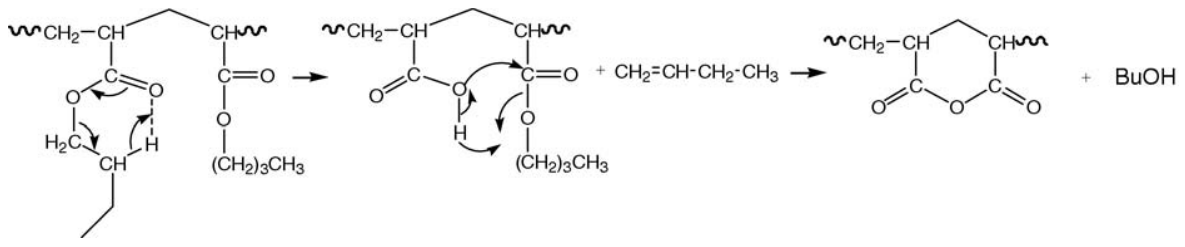

Scheme 3

anhydride $[9,14]$. Protonated PBA forms the cyclic anhydride in one step by the loss of butyl ether [illustrated in Scheme 4 for $\left(\mathrm{H}-\mathrm{PMMA}_{9}-\mathrm{H}\right)($ GlyGly $\left.) \mathrm{H}^{+}\right]$.
Once all side chains are lost, the resulting ion loses a series of low-Da masses, presumably from the cyclic anhydride units (Supplementary Figure S5).

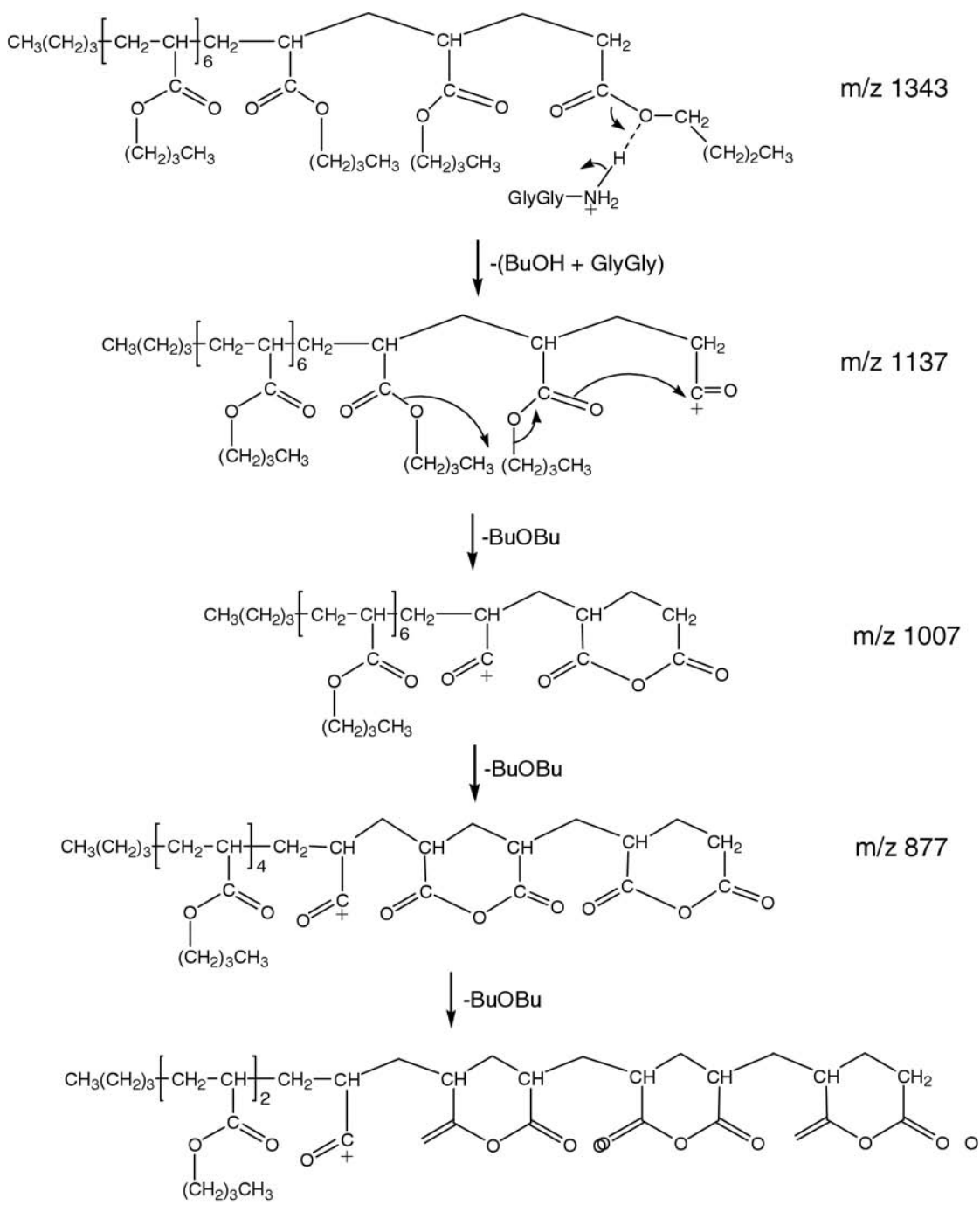

$\downarrow-$-BuOBu

$\mathrm{m} / \mathrm{z} 747$

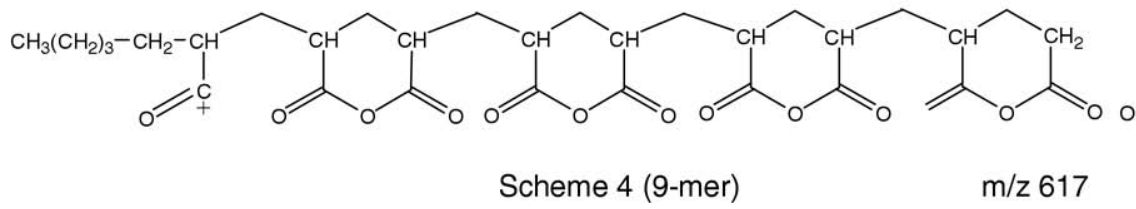

Scheme 4 


\section{Conclusion}

Protonated PMMA and PBA oligomers can be generated in the gas phase from the dissociation of protonbound complexes of the oligomers with simple protonated amino acids and peptides. Compared to their metal ion adduct analogues, these protonated oligomers undergo a unique fragmentation chemistry upon collisional activation. Both protonated oligomers fragment primarily by eliminating neutral molecules from the monomer side chains until all that is left is the backbone hydrocarbon. A computational investigation of the mechanisms generating the fragmentation patterns is under way in our group and will be the subject of future publications.

\section{Acknowledgments}

PMM thanks the Natural Sciences and Engineering Research Council of Canada for continuing financial support.

\section{References}

1. Jackson, A. T.; Yates, H. T.; Scrivens, J. H.; Bateman, R. H. The Application of Matrix-Assisted Laser Desorption/Ionization Combined with Collision-Induced Dissociation to the Analysis of Synthetic Polymers. Rapid Commun. Mass Spectrom. 1996, 10, 1668-1674.

2. Jackson, A. T.; Jennings, K. R.; Scrivens, J. H. Generation of Average Mass Values and End Group Information of Polymers by Means of a Combination of Matrix-Assisted Laser Desorption/Ionization-Mass Spectrometry and Liquid Secondary Ion-Tandem Mass Spectrometry. J Am. Soc. Mass Spectrom. 1997, 8, 76-85.
3. Scrivens, J. H.; Jackson, A. T.; Yates, H. T.; Bateman, R. H.; Gidden, J. The Effect of the Variation of Cation in the Matrix-Assisted Laser Desorption/Ionization-Collision Induced Dissociation (MALDI-CID) Spectra of Oligomeric Systems. Int. J. Mass Spectrom. Ion Processes 1997, 165/166, 363-375.

4. Gidden, J.; Jackson, A. T.; Scrivens, J. H.; Bowers, M. T. Gas Phase Conformations of Synthetic Polymers: Poly(Methyl Methacrylate) Oligomers Cationized by Sodium Ions. Int. J. Mass Spectrom. 1999, 188, 121-130.

5. Jackson, A. T.; Slade, S. E.; Scrivens, J. H. Characterisation of Poly(Alkyl Methacrylate)s by Means of Electrospray Ionisation-Tandem Mass Spectrometry (ESI-MS/MS). Int. J. Mass Spectrom. 2004, 238, 265-277.

6. Jackson, A. T.; Williams, J. P.; Scrivens, J. H. Desorption Electrospray Ionisation Mass Spectrometry and Tandem Mass Spectrometry of Low Molecular Weight Synthetic Polymers. Rapid Commun. Mass Spectrom. 2006, 20, 2717-2727.

7. Jackson, A. T. Yates, H. T. Scrivens, J. H. Utilizing Matrix-Assisted Laser Desorption/Ionization-Collision Induced Dissociation for the Generation of Structural Information form Poly(Alkyl Methacrylate). J Am. Soc. Mass Spectrom. 1997, 8, 1206-1213.

8. Polce, M. J.; Ocampo, M.; Quirk, R. P.; Wesdemiotis, C. Tandem Mass Spectrometry Characteristics of Silver-Cationized Polystyrenes: Backbone Degradation via Free Radical Chemistry. Anal. Chem. 2008, 80, 347-354.

9. Chaicharoen, K.; Polce, M. J.; Singh, A.; Pugh, C.; Wesdemiotis, C. Characterization of Linear and Branched Polyacrylates by Tandem Mass Spectrometry. Anal. Bioanal. Chem. 2008, 392, 595-607.

10. Zimmerman, P. A.; Benninghoven, A.; Hercules, D. M. Time-of-Flight Secondary Ion Mass Spectrometry of Poly(Alkyl Methylmethacrylate). Anal. Chem. 1993, 65, 983-991.

11. Yalcin, T.; Khouw, C.; Csizmadia, I. G.; Peterson, M. R.; Harrison, A. G. Why Are B Ions Stable Species in Peptide Spectra? J. Am. Soc. Mass Spectrom. 1995, 6, 1164-1174.

12. PBA Certificate of Analysis; Polymer Source Inc., Montreal, QC, Canada.

13. Fayt, R.; Forte, R.; Jacobs, C.; Jerome, R.; Ouhadi, T.; Teyssie, P.; Varshney, S. K. New Initiator System for the "Living" Anionic Polymerization of tert-Alkyl Acrylates. Macromolecules 1987, 20, 1442-1444.

14. Bertini, F.; Audisio, G.; Zuev, V. V. Investigation on the Thermal Degradation of Poly- $n$-Alkyl Acrylates and Poly- $n$-Alkyl Methacrylates $\left(\mathrm{C}_{1}-\mathrm{C}_{12}\right)$. Polym. Degrad. Stab. 2005, 89, 233-239.

15. Eastmond, G. C.; Ledwith, A.; Russo, S.; Sigwalt, P. Comprehensive Polymer Science. Polymer Reaction (Vol. 6); Pergamon Press: Oxford, UK, 1989 